\title{
PHONOLOGY, NATURALNESS AND UNIVERSALS
}

\author{
Ian Maddieson \\ University of California, Berkeley and University of New Mexicoi \\ ianm@berkeley. edu
}

\begin{abstract}
This paper briefly surveys several conceptions of naturalness in phonology, touching primarily on typological frequency and the notion of 'phonetic motivation'. It is argued that typological frequency is not a reliable indicator of what is 'phonetically motivated' as relative frequency patterns are the outcomes of more complex interactions including non-phonetic factors. Phonetic motivations are diverse and include random variations, not only deterministic results, as is often desired. Models that view phonological patterns as emerging from complex interactions of a variety of natural factors are the most satisfying.
\end{abstract}

Keywords: phonology, naturalness, universals, phonetic motivation, emergence.

\section{INTRODUCTION}

An appeal to the idea of naturalness has a long and interesting history in phonology and of course more broadly in thinking about language in general. This appeal to naturalness goes back at least to the foundations of Classical Greek philosophy, as in Plato's Cratylus, and most likely to much earlier speculations (of which we have no record) about the uniquely human attribute of language. Various concepts of naturalness continue to play a major role in the development of current models of phonology. But how valuable is this notion in providing insight into human language, and how well do the various conceptions of it serve the functions desired by advocates? The discussion will try to avoid formal issues that are specific to a given theoretical approach and consider naturalness in a very broad fashion.

Of course, there is a sense in which all the phonological patterns of any spontaneouslyacquired spoken language must be natural. Language is simply part of the biological endowment of humanity - the acquisition of language requires no formal instruction of any kind; phonological patterning is not consciously designed by the acquirer nor by those who provide the model to the learner. On the other hand, the process is culturally-determined as it is the various 'ambient' languages in different areas that are handed on across the generations, not a single uniform human speech code. And it is the fact that there is this variety of patterning across languages which prompts the idea of dividing phonological patterning into different categories. Three main principles, which are inter-related, seem to have been brought forward to form the basis of this division. One is relative frequency, which is the foundation of the tradition of empirical work on language universals. Some patterns are simply more common than others, and this fact is taken to have non-accidental foundations. A second is the notion of phonetic motivation, by which some patterns are seen as based on inherent properties of the speech chain, whether articulatory, acoustic, auditory-perceptual or cognitive, whereas others are regarded as arbitrary (and, for some, may on these grounds be excluded from phonology altogether). The third is the appeal to naturalness. This is partly a rhetorical device, particularly when a theoretical model is itself titled something like 'Natural Phonology' as this implicitly labels competing theories as 'unnatural', but it has also been used to justify a variety of formal devices or to provide 'external' support to models of various kinds. The interest here lies in what naturalness is thought to consist of and, inter alia, how it has been related to the issues of frequency and phonetic motivation. In particular, can naturalness be given a core meaning beyond these two ideas with which it is frequently associated. In the following discussion, several illustrations will be drawn from phonology textbooks because the simplifying clarity of their presentations can serve to accentuate viewpoints.

\section{NATURAL CLASSES AND RULES}

To even consider the matter of where naturalness lies in phonology it is necessary to hold that there is something real to investigate, in other words, to come down on the 'God's truth' rather than the 'hocus-pocus' side of the dichotomy famously established by Householder 
[1]. By God's truth what is meant is that there is a natural order which is to be discovered, not invented by the linguist. But whereas Householder's 'truth' was being sought in the phonological analysis of individual languages, often with an idea of discovering native speakers' intuitions, much of the more recent work treats phonology as a more global enterprise. For example, classical generative phonology and its non-linear derivatives, and Optimality Theory, as well as Natural Phonology are all more focussed on developing a model of how the phonological part of the overall language faculty might be shaped. Individual languages are mostly studied as an aide to refining the theoretical model. (In fact these theories are for the most part rather impractical as ways of writing phonologies of indvidual languages (see Dixon [2]), but that is another discussion.)

In the generative tradition naturalness was appealed to in the notion of 'natural class' segments that shared a behavior were defined by a subset of the available phonological features that mark lexical distinctions. The features relate, at least in principle, to identifiable physical properties. The feature scheme is neutrally classificatory, rather like the rows and columns of an IPA chart, and apart from the little-followed-up incorporation of markedness values in Chapter 9 of The Sound Pattern of English [3] does not distinguish between more or less natural feature values or combinations of values. It was, however, supplemented by a concept of natural rules, which largely meant that operations do not normally introduce elements that had no presence in underlying forms (or inputs), but would re-arrange the material assumed to be already present. Natural rules were opposed to 'crazy' or unnatural rules $[3,4]$. This conception of naturalness was raised to greater prominence in the non-linear phonology models that grew out of the generative tradition, as the primary device of the model is the association or de-association between linearly ordered elements on several tiers.

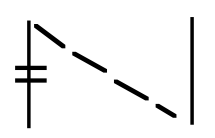

Faithfulness constraints in Optimality Theory can be viewed as representing the same general idea. So one basic concept of naturalness is no deus ex machina - phonology does not normally operate in arbitrary ways to change 'inputs' or underlying forms or whatever the basic material of lexical entries is understood to consist of.

\section{UNIVERSALS AND NATURALNESS}

But this does not satisfy the sense that the underlying material itself can be distinguished in terms of naturalness, or that different processes/patterns which are formally equivalent (e.g. by extending a feature domain to a neighboring segment) are not necessarily equally natural. For many linguists this sense derives from intuitions or observations about what is more frequent cross-linguistically. One possibility therefore is to make an explicit equation between frequency and naturalness, based on universals research. Empirical universals thus become the tool by which what is natural is detected: what is universal is natural, and what is natural is universal. This tool can be employed without asking what the underlying basis of naturalness is in any particular case. That this is a reasonably common approach is implied by a remark by Odden [6] in his introductory phonology textbook. In discussing how to select between alternative analyses he writes: "A widely invoked criterion in deciding between analyses of a language is whether the rules of one analysis are more natural, usually judged in terms of whether the rules occur more often across languages." The mention of 'rules' rather than constraints, distributional patterns, etc is not the point here, but rather the appeal to frequency as the arbiter of what is natural. Odden uses the comparison of two rules, dubbed 'labial palatalization' (3), and 'velar palatalization' (4) as an illustration of likely and unlikely rules. These may be notated in simple form as:

$$
\begin{array}{ll}
\text { labial palatalization } & \mathrm{p} \rightarrow \mathrm{t} \int / \mathrm{i}^{\mathrm{i}} \\
\text { velar palatalization } & \mathrm{k} \rightarrow \mathrm{t} \int /{ }_{\mathrm{i}}
\end{array}
$$

Odden notes that the two seem formally "hardly different ... except that the latter is common and the former is apparently not found in any language' ([6]: 252). Hence it can be viewd as unnatural.

Some problems associated with using frequency as a criterion are well known, including issues of sample structure and the accidents of historical survival which make it difficult to be certain about how to measure and 
interpret relative frequencies (as duly noted by Odden), but there is a persuasive logic to the general idea. Whatever is genuinely more frequent in languages may well be so because it is promoted over alternatives by something in the natural environment of their evolution and current use.

\section{PHONETIC MOTIVATION AND NATURALNESS}

In this way frequency becomes a proxy indicator for the 'real' natural factor or factors at play. These factors might be physical ones, but could also be ones that have to do with the structures of human social interaction. What has received the most attention is certainly what has been called phonetic motivation or phonetic grounding, based on properties of the speech production and auditory/perceptual systems shared by our species (see e.g. Ohala [7, 8], Archangeli \& Pulleyblank [9], Hayes [10]). As Kager ([11]: 11) writes: “... a second ... criterion of universality should ideally accompany typological criteria: phonological markedness constraints should be phonetically grounded in some property of articulation or perception."

Kager's illustrative example, drawing on Pater [12], concerns a postulated preference for nasal+obstruent sequences to be voiced throughout. The phonetic motivation for this pattern is argued to be the following: as the velum is being raised in the transition from the nasal to the obstruent the nasal airflow drops to a level at which the onset of an obstruent is perceived (presumably due to the low level of acoustic energy but this is not explicit in his discussion), but the flow is not yet entirely stopped and moreover the ongoing process of raising the velum is expanding the volume of the oral cavity. Both these factors allow continued airflow through the glottis as the transition to the obstruent is completed and hence voicing is facilitated ([11]: 61). Note that an initial laryngeal configuration appropriate for voicing during the nasal and the absence of a positive glottal opening gesture for the obstruent are assumed, and therefore the aerodynamic conditions allow actual vocal fold vibration to perseverate long enough into the obstruent portion to defeat the passive devoicing constraint (Ohala [8]) and thus lead to the percept of a voiced obstruent segment.

For the reasons given it may therefore be argued that $/ \mathrm{mb}$, nd, $\mathrm{ng} /$ etc rather than $/ \mathrm{mp}, \mathrm{nt}$, $\mathrm{\eta k} /$, etc are preferred or 'more natural'. What 'work' can this observation be made to perform in accounting for phonological patterns? In the OT framework in which Kager and Pater framed their discussion this phonetically motivated preference is translated into the constraint $* \mathrm{NC}$, glossed as "no nasal plus voiceless obstruent sequence". But this formulation amounts to a much more inclusive assertion than the phonetic motivation provided actually justifies. The latter only supports one 'repair' if a sequence $\mathrm{NC}$ is encountered, namely voicing it to $\mathrm{NC}_{\checkmark}$. This particular repair predicts the variants of verb stems following the /mə $\mathrm{g}-/$ prefix in the Indonesian examples in (5), but not the forms in (6) where the nasality of the prefix coda and the place of the stem onset coalesce into a single voiced nasal consonant. ${ }^{1}$

(5) /məy-/ + /bəlih/ məmbəlih 'to buy' /mən-/ + /dapat/məndapat 'to get, receive' /məy-/ + /ganti/ məyganti 'to change'

(6) $/ \mathrm{mə \eta}-/+$ /pilih/ məmilih 'to choose, vote' /mən- $/+/$ tulis/ mənulis 'to write' /mən-/ + /kasih/ mənasih 'to give'

An additional phonetic motivation is needed to get from $/ \mathrm{mb}$, nd, $\mathrm{ng} /$ to $/ \mathrm{m}, \mathrm{n}, \mathrm{n} /$ (or perhaps an alternative one to go from $/ \mathrm{mp}, \mathrm{nt}, \mathrm{nk} /$ directly to $/ \mathrm{m}, \mathrm{n}, \mathrm{n} /$ ). Patterns such as those exemplified in (6) are not hard to find elsewhere, as in the juxtaposition of infinitive prefix /ku-/ plus first person singular marker $/ \mathrm{n} /$ and verb stem in the Yao examples in (7) cited by Hyman ([13]: 155):

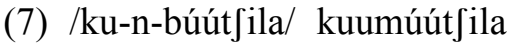 \\ 'to be angry with me' \\ /ku-n-d3íima/ kuujíima 'to begrudge me' \\ /ku-n-góneka/ kuūóneka \\ 'to make me sleep'}

We find similar patterns in lexicalized forms in (Southern British) English such as thumb $[\theta \mathrm{em}] \sim$ thimble $[\theta \mathrm{Imbl}]$, and the alternations in adjectives such as long [lon] longer [longə]. It is not hard to envisage a phonetic motivation for this $/ \mathrm{mb}, \mathrm{nd}, \mathrm{ng} /$ to $/ \mathrm{m}, \mathrm{n}, \mathrm{y} /$ pattern. For example, voiced stop bursts have less amplitude than voiceless ones, and so their presence perceptually might be missed, masked by the relatively strong amplitude of a preceding voiced nasal. Or from an articulatory point of view the simplification represented by temporally aligning the velum lowering and raising gestures with the oral closure and opening gestures represents the same kind of easing of the 
complexity of the motor control program as is represented by the nasal place assimilation that is also seen in (3-6). But this sort of exercise is playing a kind of parlor game, inventing phonetic motivations as and when they appear needed in an ad hoc fashion. It's back to a kind of hocus-pocus.

\section{PHONETIC VARIATION AS NATURAL}

There seem to me to be two problems with the way appeals to phonetic motivation have sometimes been entertained in the phonological literature. One is the temptation to over-extend the scope beyond what is motivated, as illustrated above. The other is the wish for a deterministic outcome - to take 'motivation' to mean a push in a particular direction.. From generations of work by sociolinguists, speech technologists and phoneticians we know that speech production (and the perception of what is produced) is characterized by considerable variability. Some of this variability is certainly controlled for communicative purposes, but variation in production also results from imprecise motor control of the speech apparatus, from reproducing the results of misperceptions, and from other effects that are a consequence of the fact that humans are not automata. All of this is surely natural. For example in production of a 'target' sequence $/ \mathrm{n} /$ $+/ \mathrm{p} /$ relatively small changes in the temporal alignment of the oral, velic and laryngeal gestures will produce outputs that might be perceived as $[\mathrm{np}],[\mathrm{mp}],[\mathrm{m} \mathrm{p}],[\mathrm{mb}],[\mathrm{mm}]$, among others. All of these variants are in fact diachronically attested in various Bantu languages (Hyman [13], Maddieson \& Ladefoged [14]). All are natural in the sense that the input can be used to fully predict the output, although they may differ in frequency of occurrence. This suggests that frequency and phonetic motivation are not so closely connected. Rather, many things can be considered phonetically natural, and there is not one deterministic outcome from a given configuration.

In their introduction to a collection of papers on Phonetically Based Phonology Hayes \& Steriade [15] imply that phonetic naturalness is primarily a question of 'fixing' matters of phonetic difficulty. In other words, naturalness is the inverse of difficulty. They write "OT takes on a difficulty that held back earlier approaches to naturalness: the what is phonetically difficult is not the same as the how to fix it. In a rulebased framework, one must provide the theory with multiple fixes, all of which address the same phonetic difficulty." (emphasis in the original). Although many facts of speech production and perception do clearly point in a given direction and can be understood as avoiding a difficulty Hayes and Steriade discuss the aerodynamic constraints on stop consonant voicing at some length in this connection - there seem to be others that cannot be seen as predicting a fix-up of a difficulty.

This approach, which is common in the literature on phonetically-motivated phonology, seems too take narrow a view of what the sources of natural variability are, as these do not always involve phonetic difficulty. In my view some elements that are more of the nature of 'random walk' deviations around a 'target' (cf Goldstein [16]) need to be included. In the articulatory domain these would include matters of relative timing of the different actions of the articulators, as well as variation in the amplitudes directions of articulatory gestures. In a detailed study of articulatory/acoustic relations, Goldstein showed that such random variation is far more likely to result in substantial perceptual shifting in the front-back dimension for back vowels than for front vowels given equal articulatory perturbations. Figure 1, redrawn from Goldstein's original, illustrates the acoustic spaces occupied by the variants of 7 vowel targets distributed around the vowel space (for a reasonably typical male voice) when a vocal tract model is perturbed from the original target configuration by moving the tongue center 2 $\mathrm{mm}$ in any direction. A vowel in the low front vowel area of /æ/ is very stable in acoustic terms for this given amount of random perturbation, whereas the high back vowel /u/ shows considerable 'wandering' in both first and second formant frequencies, corresponding to perceptual height and backness dimensions. Note that the acoustic scales in the figure are in linear Hz. If the axes were re-scaled to reflect auditory/perceptual distances along the F1 and F2 axes, the impact of the variation in the high back area would be shown to have even greater relative importance than that of the other vowels illustrated. This may help explain the fronting of proto-segment $* / \mathrm{u} /$ in a range of Germanic languages, including Swedish and in more recently in many varieties of English, including varieties spoken in Scotland (Wells [17]), Australia (Cox [18]), and the western United States. 

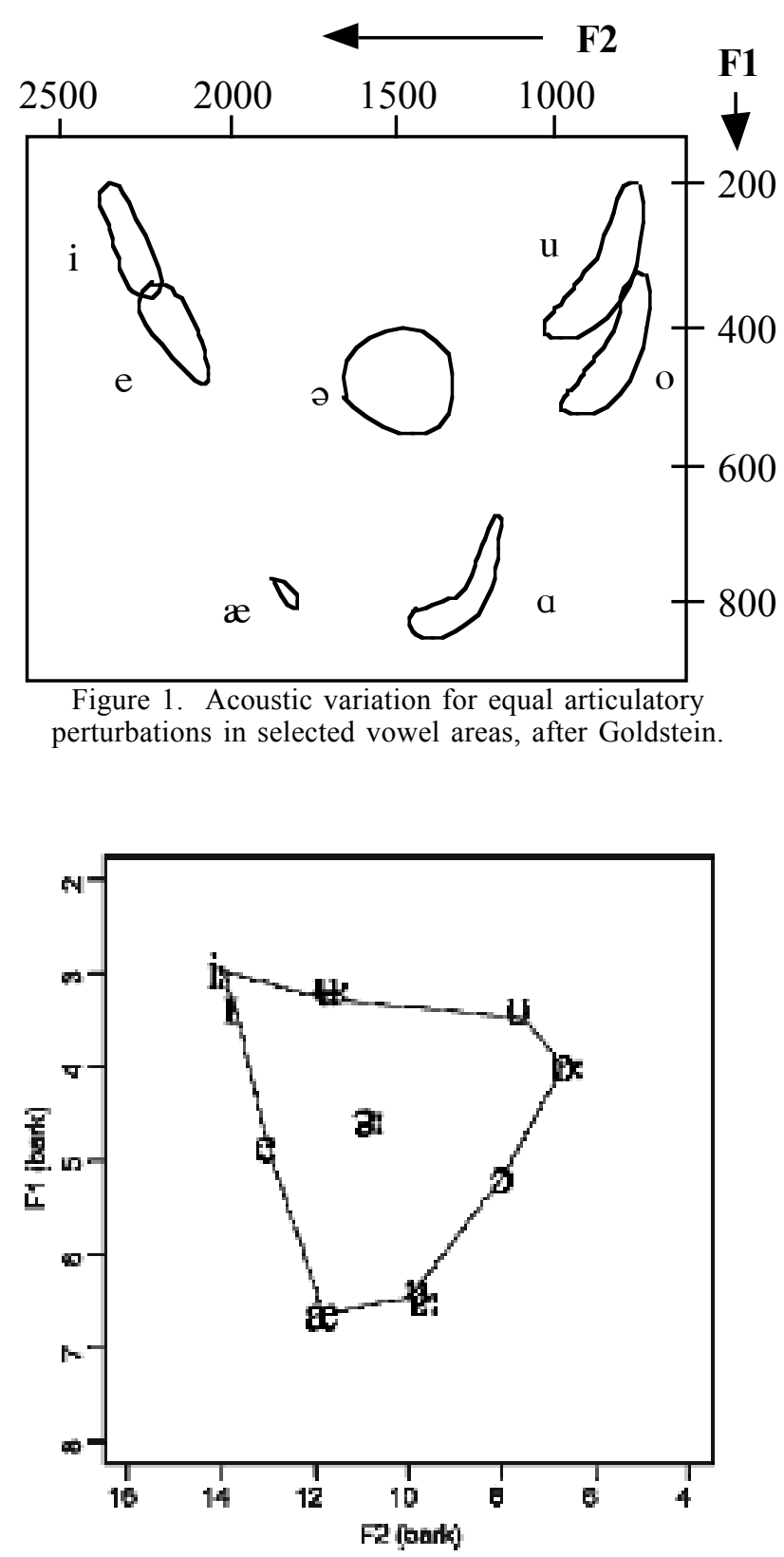

Figure 2. Mean acoustic vowel qualities for monophthongs of Australian English in Bark.

The position of monophthongal vowels in current Standard Australian English in a twoformant auditorily-scaled space is shown in Figure 2 (from Cox \& Palethorpe [19]). The vowel of a word such as boot (transcribed [ $\mathrm{t:}]$ ) is found in the front part of the vowel space. Neither theories which point to a perceptual preference for rounding with back vowels (e.g. Kaun [20]), nor those based on optimizing dispersal in the vowel space (e.g. Lindblom [21]) account for this location of the historic $* / \mathrm{u} /$, especially if the long vowel system is considered separately. But random variability due to simple imprecision of motor control hints at a possible explanation.
The structure of the lexicon also has effects that are independent of phonetic difficulty. For example, Wright [22] shows that 'easy' words (those with high frequency relative to their neighborhood density) tend to be pronounced in unpredictable contexts with more centralized vowels than 'hard' words in English. Probably this result is because learners have generalized from hearing more exemplars of 'easy' words in more predictable contexts where their articulation is reduced. The effect is not because the words themselves differ in articulatory or perceptual difficulty.

\section{WHERE IS NATURALNESS?}

There have been many interesting attempts to situate the linkage between naturalness and phonological patterning. Many practitioners of Optimality Theory are striving to incorporate phonetic naturalness directly in the grammar (but see McCarthy [23] for a critique of some aspects of this program). Natural Phonology places the 'constraints' in childhood endowment (Stampe [24], Donegan \& Stampe [25]). Others see a prime role for naturalness in guiding diachronic development (Bybee [26], Blevins [27]), or in overall models of emergence which apply over the individual's acquisition of language as well as in ongoing usage (Lindblom $[28,29]$, Boersma [30]). The attraction of this last approach is the window it opens for incorporating matters such as social interaction, random variability and generalization over the lexicon. Boersma has shown that a model that includes some random variation converges well with the predictions of a more rigid dispersion model, and Baxter et al [31] have how social networking effects might be modeled.

All of these are surely aspects of what is natural about the use of human language and should be considered in any discussion of naturalness.

\section{REFERENCES}

[1] Householder, F. W. 1952. Review of 'Methods in Structural Linguistics' by Z. S. Harris. International Journal of American Linguistics 18, 260-268.

[2] Dixon, R. M. W. 1997. The Rise and Fall of Languages. Cambridge: Cambridge University Press.

[3] Chomsky, N. \& Halle., M 1968. The Sound Pattern of English. New York: Harper and Row.

[4] Bach, E. \& Harms, R. T. 1972. How do languages get crazy rules? In R.P. Stockwell and R.K.S. Macauley (eds.), Linguistic Change and Generative Theory. Bloomington: Indiana University Press, 1-21.

[5] Anderson, Steven A. 1982. Why phonology isn't 'natural'. Linguistic Inquiry 12, 493-539.

[6] Odden, D. 2005. Introducing Phonology. Cambridge: 
Cambridge University Press.

[7] Ohala, J. J. 1974. Phonetic explanation in phonology. In Papers from the Parasession on Natural Phonology. Chicago Linguistic Society, 251-74.

[8] Ohala, J. J. 1983. The origin of sound patterns in vocal tract constraints. In MacNeilage, P. F. (ed.), The Production of Speech. New York: Springer, 189-216.

[9] Archangeli, D., and Pulleyblank, D. 1994. Grounded Phonology. Cambridge MA: MIT Press.

[10] Hayes, B. 1999. Phonetically driven phonology, the role of Optimality Theory and inductive grounding. In Darnell, M., Moravcsik, E., Newmeyer, F., Noonan, M., \& Wheatley, K. (eds.), Functionalism and Formalism in Linguistics. Amsterdam, John Benjamins.

[11] Kager, R. 1999. Optimality Theory. Cambridge: Cambridge University Press.

[12] Pater, J. 1999. Austronesian Nasal Substitution and Other NC Effects. In Kager, R., van der Hulst, H., and Zonneveld, W,, eds.,. The Prosody-Morphology Interface. Cambridge: Cambridge University Press, 310-343.

[13] Hyman, L. M.. 2001. On the limits of phonetic determinism in phonology, *NC revisted. In Hume, B. \& Johnson, K. (eds), The Role of Perception in Phonology. San Diego: Academic Press, 141-185.

[14] Maddieson, I. \& Ladefoged, P. Phonetics of partially nasal consonants. In Huffman, M. K. \& Krakow, R. A (eds.), Nasals, Nasalization and the Velum. San Diego: Academic Press , 251-301.

[15] Hayes, B. \& Steriade, D. 2004. Introduction, The phonetic bases of phonological markedness. In Hayes, B., Kirchner, R. \& D. Steriade, D. (eds.), Phonetically-based Phonology. Cambridge: Cambridge University Press, 1-33.

[16] Goldstein, L. M. 1983. Vowel shifts and articulatoryacoustic relations. In Cohen, A. \& van den Broecke, M. P. R. (eds.), Abtracts of the 10th International Congress of the Phonetic Sciences. Foris Publications, Dordrecht, 267-273.

[17] Wells, J. C. 1982. Accents of English. Cambridge: Cambridge University Press

[18] Cox, F., 1999. Vowel change in Australian English. Phonetica,56, 1-27.

[19] Cox, F. \& Palethorpe, S. To appear. An Illustration of the IPA: Australian English, Journal of the International Phonetic Association.

[20] Kaun, A. 2004. The typology of rounding harmony. In Hayes, B,. Kirchner, R. Steriade, D., (eds.), Phonetically-based Phonology. Cambridge: Cambridge University Press.

[21] Lindblom, B. 1986. Phonetic universals in vowel systems. Ohala, J. J. \& Jaeger, J. J., (eds.), Experimental Phonology. New York: Academic Press, 13-44.

[22] Wright, R. A. 2003. Factors of lexical competition in vowel articulation. In Local, J. K., Ogden, R., \& Temple, R. A. M. (eds.), Phonetic Interpretation (Papers in Laboratory Phonology VI). Cambridge: Cambridge University Press, 75-87.

[23] McCarthy, J. J. 2002. A Thematic Guide to Optimality Theory. Cambridge: Cambridge University Press.

[24] Stampe, D. 1979. A Dissertation on Natural Phonology. Garland Press: New York.

[25] Donegan, P. \& Stampe, D. 1979. The study of Natural Phonology. In Dinnsen, D. A. (ed.). Current Approaches to Phonological Theory. Bloomington: Indiana University Press, 126-173.

[26] Bybee, J. 2001. Phonology and Language Use.
Cambridge: Cambridge University Press.

[27] Blevins, J. 2004. Evolutionary Phonology, The Emergence of Sound Patterns. Cambridge: Cambridge University Press.

[28] Lindblom, B. 1983. Economy of speech gestures. In Peter F. MacNeilage (ed.), The Production of Speech. New York: Springer-Verlag, 217-245.

[29] Lindblom, B. 2000. Developmental Origins of Adult Phonology, The Interplay between Phonetic Emergents and the Evolutionary Adaptations of Sound Patterns. Phonetica 57, 297-314.

[30] Boersma, P. 1998. Functional Phonology. The Hague: Holland Academic Graphics.

[31] Baxter, G., Blythe, R., Croft, W. \& McKane, A. J. 2006. Utterance selection model of linguistic change. Physical Review E , 73, 046118.

[32] Pater, J. 2001. Austronesian nasal substitution revisited. In L. Lombardi, (ed.) Segmental Phonology in Optimality Theory, Constraints and Representations. Cambridge: Cambridge University Press, 159-182.

${ }^{1}$ I ackowledge that Pater [32] later revised his ideas on the role played by the $* \mathrm{NC}$ constraint on this issue. See also Hyman [13] for cases where 'inputs' /mb, nd, $\mathrm{gg} /$ appear as /mp, nt, $\mathrm{nk} /$ 